\title{
Information overload in a data-intensive world
}

\author{
Tibor Koltay \\ Eszterházy Károly University, Faculty of Pedagogy, Institute of Learning Technologies, 5100 \\ Rákóczi út 53, Jászberény, Hungary \\ Koltay.Tibor@uni-eszterhazy.hu
}

This is the author's accepted manuscript of "Information overload in a data-intensive world". In Schuster A (ed.) Understanding Information: From the Big Bang to Big Data. Cham: Springer International Publishing, 2017. pp. 197-217.

\begin{abstract}
This chapter investigates the complex phenomenon of information overload that, despite controversies about its existence, is a major problem, the symptoms of which have to be alleviated. Its sources and nature in academia, business environments and in everyday life information seeking, its particular features in the data-intensive world are described, not forgetting about the role of information technology. The possible ways of mitigating information overload are specified, underlining the imperative of being critical against information. Potential approaches and tools, described in this chapter include utilising appropriate information architecture, applying information literacy, data literacy and other literacies, as well as making use of personal information management.
\end{abstract}

Keywords: Information overload, information literacy, information architecture, coping strategies, critical thinking, critical reading, filtering, personal information management.

\section{Introduction}

This chapter investigates information overload (IO), a phenomenon that was described by Bawden and Robinson as perhaps the most familiar one from among a recently articulated group of phenomena that can be called 'information pathologies' [1].

Examining IO requires some understanding of concepts, such as data, information and knowledge. Among these concepts, perhaps, information is one of the least understood concepts, albeit widely used in its everyday, technical and scholarly meaning. It is typically defined in terms of data, though the implicit challenge is to understand and explain how data is transformed into information, and information into knowledge [2]. As to the relationship between data and information, the boundaries between them have never been rigid, and if there are boundaries at all, they are often blurred [3]. Nevertheless, these terms are important and will appear in this chapter several times, although with varied frequency. However, since these terms cannot be explained in their entirety in this writing for various reasons, questions related to the difficulty of differentiating data, information, and knowledge have been deliberately set aside.

In order to provide a general understanding about the issue of information overload and the various dimensions associated with it, this chapter has the following organization. Section 2 describes the general characteristics of information overload (impacting academia), and gives details about its nature in business environments and in everyday life information seeking. The role of information technology is explained, not forgetting about information overload in today's data-intensive world. Section 3 charts the spheres of activities, where alleviating the symptoms of information overload can be endeavoured. One broad sphere is using the tools and methods of design and information architecture. 
An even broader sphere of activities is related to different ways of interacting with information. In this subsection of the chapter, it is explained, how taking a critical stance may help in mitigating information overload, and it is argued that a feasible framework for looking critically at information is provided by a number of different literacies that are described in detail. The prospects of making use of personal information management (PIM) tools and related new, hybrid concepts, operating on this level, are also outlined.

\section{Information Overload}

Information overload is sometimes qualified as a modern-day myth [4]. Some argue that we do not know enough about it [5], among other things, because it often remains unrecognized [6]. Nonetheless, it is a major problem that affects all spheres of our life [1]. In many cases, the incurring material costs and losses that can be ascribed to IO are estimated to be high [7].

Information overload does exist, at least as a perceived difficulty or burden. For instance, the results of a mixed methods quantitative and qualitative study by Benselin and Ragsdell in 2015 found that people in most age groups equally think that they have suffered from IO [8].

Information overload can be defined as an impediment to efficiently using information due to the amount of relevant and potentially useful information available. It can cause delays in decision making. Usually, it is associated with a loss of control over a situation, or with being overwhelmed [1].

It seems to be obvious that the concept of information overload involves the notion of excess. However, excess in itself is not a sufficient condition for being overloaded. Overload can be defined rather in comparison to some norms, which regulate what is an appropriate amount of information and which pieces of information are undesirable [9]. These norms are varied, depending on the given task. Therefore they are not fixed, not speaking about being codified in any way.

\subsection{General Characteristics of Information Overload}

Usually, information overload is not caused by a single factor, but has several causes that influence two fundamental (though not exclusive) variables. The first variable is information processing capacity, which is a personal characteristic. The second variable is determined by the nature of the task or process. Thus, IO originates in an environment of information processing requirements, measured in terms of available time, because, usually, a given amount of information has to be processed within a certain time period. If an individual is capable to process only a smaller amount of information than required in the determined timeframe, information overload is present. Therefore, the limitations of an individual's ability to process information, compared to the amount of information received are a decisive factor of IO [10].

The three main settings, where IO appears are academia, business and everyday life. Accordingly, we can experience the following types of IO:

- Information overload in academia, impacting faculty, researchers and students;

- Information overload in business environments impacting the employees (decision makers and other members) and customers;

- Everyday information overload of the general public.

Beyond IO, which is experienced on a personal level, there is information overload that impacts organizations [11].

The excessive quantity of information, often labelled as Too Much Information (TMI) represents the macro level of IO [7]. Caused by the limits of physical storage and processing capacities that impede access to information, this level is identified as one of the major contributing factors of IO [1]. However, the quantitative growth of information is not only a continuation of the expansion experienced in earlier times. It is also present due to the ease of publishing and storing information on the internet that is not coupled with incentives to remove unnecessary (i.e. outdated or irrelevant) information [12]. In addition to this, we have to handle greater variety of formats and types available, delivered through a limited number of interfaces [1]. Furthermore, a substantial part of information that we consume and have to manage is becoming utterly volatile [12]. 
IO is often a condition of being overwhelmed and under-informed at the same time. Although this can be qualified as a rare sentiment, it is a state of mind that characterizes our information environment. In this situation, the amount of information may be less critical than the extent to which the information is structured and the form of being structured, in as so much it permits decision making, based on relevance judgements [13]. Essentially, this phenomenon shows similarity to a situation, where we may be overloaded because we are drawn toward information that in the past did not exist or that we did not have access to, but is available now [14].

Conceiving information overload depends to a significant extent on how we understand the nature of information. The three principal uses of the word 'information' are the following ones:

- Information-as-process, i.e. the act of informing;

- Information-as-knowledge, i.e. knowledge communicated concerning some particular fact, subject, or event;

- Information-as-thing, i.e. objects, such as data and documents, which are regarded as being informative [15].

This latter use refers to objective packages of cognitive content in a certain form. Such understanding covers recorded information, which is paramount in generating IO [16]. Notwithstanding, information-as-thing is associated with practically all forms of IO and is not conceivable without information-as-process and information-as-knowledge.

Complaints about information overload itself are hardly new. Resentment at facing the difficulty to keep up with the amount of information available began early. The growth of information in printed books, scholarly journals, and then by computers, has often been named as the source of IO. Information overload was generally accepted as a problem in the late 1950s and early 1960s, ascribed mainly to the expansion of publication, particularly in science, technology and medicine. By the 1990s references to information overload began to appear in the business world, as well [1]. In recent times, $\mathrm{IO}$ is the result of wide availability and widespread use of social media tools and services. Therefore, social media is largely blamed for the massive increase in information that causes not only abundance, but also raises questions of quality and trust in information [8].

\subsection{Information Overload in Business Environments}

The impact of IO is usually different in specific business areas [10], yet in business organizations, employees lose productive time when they have to deal with information of limited value [14]. Such losses impact organizations far beyond its decision-makers.

The restricted information processing capacity of employees, caused by the complexity of tasks, the need for managing parallel projects or tasks are frequently mentioned [10]. Frequent interruptions in the work processes represent a serious burden, because employees, interrupted in answering a given message by another one, not only lose time, but have to recover from the interruption and refocus their attention [14].

Managers are typically overloaded by too much information because they have to justify decisions, so they feel the need to collect information in order to indicate their commitment to rationalism and competence, believed to improve decision-making. They receive enormous amounts of unsolicited information, then they seek more information to verify the information that they have already acquired. In many cases, managers collect information because it may be useful, and because they want to acquire all possible information. Last, but not least, they regard information as a currency that may make them indispensable to a certain extent [11].

If organizational design is changed, a higher level of information processing requirements appears, while better coordination through standards, common procedures and rules can reduce the information processing requirements [10]. Needless to say that overload, produced by the organization is experienced by its individual members.

In cross-cultural business communication, the appearance of IO is related to the ways, how people receive and decode information, mainly in textual form. These differences originate in the variety of professional, corporate and rhetorical styles that are defined by cultural styles, causing differences between varied nations. However, differences within a given culture are less important than the extra cognitive load, caused by having to process information, conceived in a different cultural framework, thus based on different discourse patterns [17]. 


\subsection{Information Overload in Everyday Life Information Seeking}

Besides IO in academic and professional (first of all business) environments, everyday life information seeking also plays a role, even though it received less attention [14]. This type of IO is experienced similarly to that in other environments [18]. The concept itself refers to the acquisition of various informational (both cognitive and expressive) elements which people employ to orient themselves in daily life or to solve problems [19].

Everyday life information seeking is often connected to disposable information, i.e. information that is used once and then discarded. The background to discarding information is that people are only willing to make an effort to get quality information if they foresee further, continued use of that information. Disposable information is usually directed towards satisfying the need for quick answers to minor questions [20]. By its very nature, social media, used for everyday use produces masses of disposable information.

While the existence of disposable information seems evident, it is questionable if professional environments produce it or not. It is tempting to say yes, because a given piece of information is often used to provide a base for a unique investigation and/or publication. However, it is rather obvious that research - be it for academic or business purposes - is built on sophisticated processes that allow or require the repeated use of an idea, triggered by a piece of information. Ideas, as we know, have the potential to serve as the rough material of newer investigation and/or publication, albeit their use may be conscious or not.

\subsection{The Role of Information Technology}

As already mentioned, the use and misuse of information technology has been blamed for causing information overload already in the 1980s and 1990s, and it continues to be a major source today.

Actual information and communication technologies make use of information pull and push. Either can cause IO and display the symptoms of the loss of control of information [21]. The pull approach to information stands for the standard method of retrieving information. Push technologies cover automatic delivery based on pre-defined information profiles. Both have strengths and weaknesses, so the best approach might be to use them in complimentary ways [18].

A somewhat different issue is the (already mentioned) influence of social media, which is tangible in the corporate world, in everyday life information seeking and - to a lesser extent - in scholarly research. Social media is widely characterised by uncontrolled communication, due to the ease of producing information with Web 2.0 tools and the expectation of constant novelty that requires rapid updating and posting of new material. All of them contribute significantly to an enormous growth in the quantity of information.

\subsection{Information Overload in the Data-Intensive World}

In 1996, Bradford and Wurman wrote about a 'tsunami of data' [22] that has been more frequently named a 'data deluge', resulting from the existence and availability of high bandwidth networks that have the capacity to store massive amounts of data [23]. The prevalence of data in everyday life, in the business world and as research data in the natural sciences, the social sciences and the humanities significantly contributes to IO.

An emergent and important, though not exclusive facet of the data-rich world is 'big data' that is conditioned by the interplay of cultural, technological and scholarly phenomena [24]. The first and most straightforward measure, by which big data can be defined, is volume, even though views on it also depend on the conceptions in the given field of research. The second measure is variety, which is about managing the complexity of multiple data types. Data is in motion at accelerated speed that causes difficulty in capturing and processing it, thus velocity represents an important dimension [25].

Apparently, information overload, caused by the abundance of data could be called 'data overload'. Whatever the name, it impacts both individuals and organizations in the academic and the business sphere, as well as in everyday settings. 
The case of the digital humanities prototypically shows the role and importance of data in today's research. The digital humanities has been led to a substantial extent by the assumption that data can be interpreted as texts, and - conversely - texts can be interpreted as data. While being interested in recorded information, i.e. information-as-thing, most - if not all - digital humanities projects rely on some kind of data $[26,27,28]$. Data for the digital humanities is a machine-actionable abstraction that characterizes some aspects of a given object [29]. The technology, used by the digital humanities to create new objects for humanistic interrogation [30] may be extended to media consciousness of the digital age [31]. This may contribute to the proper understanding of the growing digital infrastructure's effects on all kinds of information. Such thinking also may be broadened to the act of thinking critically about the ways, how knowledge in the 21st century is transformed into information through computational techniques [32]. Consequently, there is a need for acquiring a deeper general understanding of the mutual co-constitution of technology and of the human component and interrogating the possibility of positively influencing the existing cyber-infrastructure $[33,34]$.

\section{Alleviating the Symptoms of Information Overload}

There is an ever widening gap between information that is available to us and which is usable, because both inbound and outbound flows of information, i.e. information, exploited when consuming and when producing and/or distributing information may not be appropriate to someone's information needs [5]. There is no single cure to information overload, because it has several and complex causes. In order to be successful, barriers have to be surmounted and the most efficient measures and tools for discovering, identifying and properly using information have to be found. [1].

We have pointed out that Too Much Information represents the quantitative side of IO. Arguably, the problem is not that there is too much information. In an information-driven society there cannot be too much information. Information overload represents the challenge to make effective use of information, thus instead of blocking or limiting, there is a need for finding appropriate tools for discovery [34]. This can be achieved mainly on the micro-level of overload that is qualitative, because it is essentially caused by a failure to filter information [7]. Filtering mechanisms provide help in recognising value-added information to resolve the dilemma of receiving too much information, vs. not receiving the right piece of information, or not getting enough of the right information $[35,36]$.

While IO on the quantitative, macro-level in itself cannot be influenced directly, there are two different broad spheres of activities, where we can venture alleviating the symptoms of qualitative (micro-level) information overload:

1. When designing information;

2. When interacting with information.

\subsection{Design and Information Architecture}

Ill-structured, unclear information causes IO. However, if we can improve the conciseness, consistency and comprehensibility of information, the level of information processing capacity of the individual can increase [10]. In other words, the presentation of information, such as its organization, selection, and format, on webpages and in other forms plays an important role in reducing information overload [38]. That is the reason, why sound reasoning dictates that information architecture (IA) that goes beyond simple design issues, should play an important role in helping people and organizations to successfully mitigate information overload [4], because it can offer solutions to avoid micro-level IO conditions [7].

Information architecture explores ways to organize and create semantic and contextual informational relationships that accommodate user goals and behaviour [39]. It addresses informationas-thing, but it is also directed towards facilitating acts of informing (information-as-process) and information-as-knowledge, in the sense of fostering the process of information being transformed into knowledge. 
Adequate design of information systems is part of IA and the elimination of IO is not imaginable without it. Designers have to take into account differing motivations and mental models for handling information of different users [40]. Therefore, the prerequisite of providing adequate design is to have a deep understanding of their users and of their social context among the conditions of growing complexity that emerges in diverse and abundant information choices in almost all fields [41].

Organization and representation occupy an important position in IA, and materialize in the concept of findability, which is the art and science of making content findable [40]. A special, practical field of enabling findability is developing recommendation systems as it was done by Huang et al, who proposed a personalized guide recommendation system to mitigate IO that encumbers museum learning, i.e. people's use of museums to acquire knowledge, because learners have to decide if certain parts from a mass of information needs to be retained, or discarded [42].

Sometimes, we may face arguments that there is no need for IA, because users can do the same, what the experts used to do for them [43]. In spite of this, architecture is never superfluous, and if we let users manage information for themselves, the information architectures that evolve may have more chance to work inappropriately [5]. This is one of the reasons why proper design also requires an understanding of the differences between professionals and amateurs. Ideally, every information creator would be an expert in producing information [44]. However, not everyone has accumulated enough expertise, because a substantial part of users are amateurs, who love to be engaged in a particular activity, independently of the fact whether they are knowledgeable or not of their respective subject [45]. Amateur settings are thus often different from professional environments that foster information use by members of a given profession or discipline. Amateur users, who act as creators, concentrate on their own immediate needs, and do not have a precise idea of other users' needs or the necessity of meeting these needs [44]. Certainly, we should not forget about professional amateurs (Pro-Ams), who constitute an intermediate category between amateurs and professionals. They play an important role in fields that are too complex to generate mass popularity, but not sophisticated enough to be removed entirely from the popular realm [46, 47]. It comes as no surprise that IO is differently perceived in and by these groups.

In general, combating information overload fits well into the thought of social usefulness of IA, because it describes the process of designing, implementing and evaluating humanly and socially acceptable information spaces [34]. Nonetheless, the effects and tools of information architecture alone are limited, because information architects and user experience designers can discover information overload only retrospectively and through indirect means [5]. Notwithstanding, information architecture is just one facet in the complex of interactions that contribute to the user's overall experience with an information resource [40].

\subsection{Interacting with Information}

IO is a human experience, thus - being fundamentally propagated by people - technology cannot solve this problem entirely [7]. Therefore, alleviating the symptoms of IO when interacting with information is clearly attached to the micro-level of IO and has at least two sets of approaches:

1. Taking a critical stance on information;

2. Applying personal information management (PIM) tools.

\subsubsection{Being Critical against Information}

Taking a critical stance is a crucial condition of successfully mitigating information overload. Any critical approach to information presupposes the existence and use of competencies, i.e. the combination of skills, abilities and tools, often not clearly distinguishable from each other.

Being able to recognize the quality of a given message is a key skill. It has become especially important in the present-day information environment, where we experience the prevalence of social media services and tools. The changes in perceiving trust and authority dictate the need for assessing content that involves not only finding authoritative sources, but a self-awareness of someone's own worldview and biases [48]. 
Critical thinking materializes to a substantial extent in critical reading, which requires us to do the following:

- Determining the purpose of the text and assessing how the central claims are developed;

- Making judgements about the intended audience of the text;

- Distinguishing the different kinds of reasoning in the text;

- Examining the evidence and sources of the writing [49].

If we want to be efficient and successful information users, searching for information has to be critical in the sense that it is based on having a clear picture about the information and data landscape of the given discipline or profession. It has to be understood that in many cases there is a need to determine the validity of the information created by different authorities and to acknowledge that some sources of authority are privileged over others. Therefore, complex search strategies can make a difference to the breadth and depth of information found. Searching for new tools to solve new questions may be required, so it has to be understood that relying always on familiar resources is not appropriate in all cases [50]. It is crucial to understand that first attempts at searching do not always produce adequate results. It is similarly important to remain persistent when facing search challenges, then recognizing when there is enough information to substantiate a decision if the given information task has been completed or not. Efficient searching presupposes utilizing divergent and convergent thinking that is exemplified by brainstorming and selecting the best source, respectively. Based on search results, needs and further search strategies can be refined. This has to be done despite the reputation of general search engines, first of all the sweeping popularity of Google, and the widespread beliefs about the straightforward and uncomplicated nature and easiness of searching for information. There may be also a need to identify specialist search tools, appropriate to each individual information need and to understand the value of controlled vocabularies and taxonomies in searching. Formats should not be equated with the underlying creation process, because the ambiguity that surrounds the potential value of information in emerging formats and modes has to be taken into consideration. Making informed choices regarding someone's online actions in full awareness of issues related to privacy and the commodification of personal information is also desirable, but fairly difficult, because the spirit of social media does not support critical approaches to information [48].

Influencing the speed of access to information and its consumption also pertains to being critical against information. The accelerated pace of life brought with it an increase in the speed of accessing and using information, resulting in rapid consumption of information that causes IO. Nonetheless, this kind of overload could be mitigated by applying slow principles [1]. Being slow is not identical with doing something less rapidly. It is rather being concerned with control by judging the right speed and tempo for a given activity and the context, with a reflective attitude. Slow principles provide a framework for making balanced choices appropriate to a given situation by creating enough time and space to make choices that may prove beneficial. However, this may seem impractical and impossible because of the constant pressure to consume and produce information. Instead of completely "unplugging", the purposive withdrawal from some informational activities, like declining to publish Twitter updates, while still maintaining an account might be suitable. Reading deeply and exclusively from one source, or just doing the opposite, i.e. browsing web material without a pre-defined direction or need, may provide breathing spaces outside the dominant social tempo. Apparently, there are situations, where a slow approach is undesirable, as for instance when we check trivial facts [21]. Slow principles clearly demonstrate the importance of time sensitivity that is related to the perception of being overloaded due to the limitation of time for reviewing available information. Time constraints become even more profoundly obstructing in the case of decision making, especially if critical decisions have to be made [13].

\subsubsection{Making Use of Varied Literacies}

A feasible framework, for looking critically at information is provided by a number of different literacies that help to understand the digital world better and to take meaningful courses of action, because what is digital, is subject to human agency and to human understanding [51].

The term literacy is closely related to literature, which originally combined the meaning of being knowledgeable with the body of writing of aesthetic merit. Later it began to cover skills by wide masses to handle texts disregarding if they are part of the literary canon or not. In any way, literacy 
seemed to be well understood and properly defined. However, the growing role of digital technologies changed its meaning [52, 53, 54]. Therefore, literacy is contingent on social and cultural practices, thus not limited to cognitive factors. This is one of the reasons, why literacies are often called 'new' by being identified within varying social and technological contexts [55, 56].

The complex and broad forms of literacies are not restricted to any particular technology and foster understanding, meaning and context, and they cannot be conceived without taking notion of reading literacy, which can be defined as an individual's ability to understand printed text and to communicate through print. In a broader sense, literacies involve the integration of listening, speaking, reading, writing, and numeracy and are closely tied to functional literacy that most commonly denotes the ability to read and use information essential for everyday life [57]. Literacies clearly encompass and emphasize efficient information retrieval [58], but they should go beyond caring for the abilities of finding information, thus include the creation of information, mainly, though not exclusively, in the form of writing [44]. Let us add that information architects do not negate that functioning in modern society requires the mastery of written communication [41].

If we understand culture as a complex of codes and meanings, on which human communication depends [15], any kind of literacy is cultural knowledge, because it enables us to recognize and use language that is - as stated earlier - appropriate to different social situations [59]. However, being broad in scope, literacies are also tied to technology [60]. Literacies also build a foundation for higherlevel skills and abilities of recognizing, analysing and understanding the context and relationship between language, information and knowledge [61]. In other words, they help to "transform information into knowledge and knowledge into judgment and action" [62].

Information literacy (IL) is one of the standard literacies, which refers to the use of information and communication technologies to retrieve and disseminate information, to the competences to find and use information in information (re)sources, as well as to the process of recognizing information need, finding, evaluating, and using information to acquire or extend knowledge. By its breadth and by being associated with lifelong learning, it enables the efficient processing of all types of information content. It has been relevant to, and supportive of activities in personal, social and economic spheres. Information literate people are able to recognize when information is needed. They are equipped with skills to identify, locate, evaluate, and use information in order to solve a particular problem [63, 64, 65].

Originally information literacy was dominated by questions of access, because it has been dealing with media that have been far from accessible [51]. This has changed now, as there is overabundance of information. Therefore, presently we suffer from information overload in a higher extent than ever. This circumstance substantiates the need for adjusting IL to the properties of the digital environment [66]. This is reflected in a newer and up-to-date definition, where IL is characterized as a set of integrated abilities encompassing the reflective discovery of information, the understanding of how information is produced and valued, and the use of information in creating new knowledge and participating ethically in communities of learning [48].

Besides IL, there are a number of other literacies. Many of them can be qualified as overarching, and share a number of features. For instance, metaliteracy informs other literacy types, while it fosters critical thinking, emphasizes content and participation via social media. It is meant to expand the scope of information literacy as more than a set of discrete skills [67]. The newest framework for information literacy, conceived for the higher education draws significantly upon metaliteracy [48].

Transliteracy comprises the ability to read, write and interact across a range of platforms, tools and media. While being a comprehensive concept, it is not meant to replace any of the format-specific literacies, and it is not tied to any particular technology. It analyses the social uses of technology, by focusing on the relationship between people and technology, most specifically social networking. With this, it also intends to break down barriers between academia and the wider community [68]. Similarly to transliteracy, digital literacy does not lower the standing of traditional literacies, thus it is much inseparable from reading, writing and arithmetic [69]. Accordingly, it is built on both traditional literacy skills, first of all taken from the information literacy domain, while having orientation on understanding of twenty-first century socio-technical systems, thus reflecting that ordinary people became not only receivers, but also senders of messages [56, 70]. Obviously, most up-to-date forms of literacy recognise the role of information production. 
Digital literacy serves the identification, access, management, integration, evaluation, analysis and synthesis of digital resources, thus it is made up of awareness, attitudes and abilities, directed towards appropriately using digital tools and facilities. It concentrates on the context of specific life situations. It advances the construction of new knowledge and the creation of media expressions. Therefore, it fosters communication and constructive social action, as well as reflecting on them [71]. The distinctive feature of digital literacy is that it is associated with many things or even includes them, without claiming to own them. For instance, it encompasses the presentation of information, without incorporating creative writing and visualization. It includes the evaluation of information, without regarding systematic reviewing and meta-analysis to be its property [72].

Data literacy is not without antecedents, and it is also closely connected to information literacy. Nonetheless, it brings in a new facet to the world of literacies by the fact that it is tied to data, the importance of which is becoming widely accepted. Data literacy appears under different names, such as data information literacy, science data literacy or research data literacy. Nonetheless, the term 'data literacy' is more suitable by being simple and straightforward [73], and does not restrict the concept to research data. Data literacy's closeness to IL becomes evident if we look at one of its definitions that underline the ability to process, sort, and filter vast quantities of information, which requires knowing how to search, how to filter and process, and to produce and synthesize it [74].

In a matrix of data literacy competencies, quality evaluation appears as the perhaps most important activity. It includes assessing data sources for trustworthiness, errors and other problems. Evaluation appears already when we collect data [75]. Data quality is determined first of all by trust, which is complex in itself, as it includes the lineage, version and error rate of data [15]. Trust depends on subjective judgements on authenticity, acceptability or applicability of the data; and is also influenced by the given subject discipline, the reputation of those responsible for the creation of the data, and the biases of the persons, who are evaluating the data. Quality data can display authenticity, when there is sufficient context in the form of documentation and metadata. Data also has to be usable that presupposes that it is discoverable and accessible. Integrity of data assumes that the data can be proven to be identical, to some previously accepted or verified state [76].

The need for critical assessment mentioned above, occupies a distinguished place also among the general features of data literacy. Being critical in this environment includes giving emphasis to the version of the given dataset, the person responsible for it [77], as well as understanding what data means, including how to read graphs and charts appropriately, draw correct conclusions from data, and recognize when data is being used in misleading or inappropriate ways [78]. Being familiar with the context in which data is produced and reused can be a decisive factor in evaluation [79]. Profound understanding of the big data phenomenon is an essential aspect of data literacy [24]. Primarily, quality assurance is regarded to be the ability to recognize a pattern or consistency in the data, facilitated or disrupted by the quality of documentation (metadata). In the case of research data, quality assurance requires synthesis, because it is a blend of technical skills, disciplinary knowledge and metacognitive processes [78].

Besides managing quality, data literacy has to give attention to data organization and preservation. Data interpretation is becoming more and more crucial, and clearly shows the mechanisms that also characterize information literacy. As an important technique of interpretation, data visualization comprises creating, evaluating and critically assessing graphical representations of data. Besides visualization, presenting data verbally in a clear and coherent manner is also a crucial data literacy competence [75].

All these competencies rely on the ability to translate vast amounts of data into abstract concepts and to understand data-based reasoning, especially if it is coupled with the understanding that data has limitations and we must remain able to act also in the absence of data [80].

\subsubsection{Applying Personal Information Management Tools.}

The discussion above was built on the idea that there are different levels, where micro-level IO can be mitigated. One of them is given by information architecture that concentrates on the relationship between relatively well-defined actors, i.e. architects and their target audiences. Literacies operate on a more collective, societal level. 
In addition to these levels, there is a third level, where the creator of information is less visible, or does not play a substantial role. This is the personal level, where the needs and the role of the user appear to be more markedly emphasized than the ones of the creator. Being an activity in which an individual stores personal information items in order to retrieve them later, personal information management (PIM) operates on this level [81].

PIM is "both the practice and the study of the activities a person performs in order to acquire or create, store, organize, maintain, retrieve, use and distribute the information needed to complete tasks (work related or not) and fulfil various roles and responsibilities" [82, p. 453].

PIM practices consist of finding information and retaining this information for future re-use. It also includes disposing of information, if it is judged to be unusable or nor worthy of the effort and/or physical space to archive it. These two basic activities (and especially retaining information) are accompanied by meta-level activities, such as measuring, evaluating and organising information and making sense of it. It is also important to maintain the flow of information and manage privacy [82].

PIM tools offer solutions, which can help in decreasing fragmentation that characterizes our information environment. This fragmentation is caused by the ambiguity, novelty, complexity and intensity of information itself and the diversity of formats, applications and tools [83]. As popular interest in personal digital information grows, personal information management has to be explored for its potential as a service, offered by different institutions, first of all, by libraries [84].

By its origin, information, managed through PIM activities, can be either public, or produced by people themselves. Both types can be present in the PIM environment of the same person at the same time. For instance, researchers receive or collect information, produced by others, while they also conserve their own publications. In other words, consuming novel resources is often supplemented by conserving large amounts of information for future consumption. This means that people extensively preserve and curate information. Usually, they go beyond keeping information passively by making attempts to organize it in order to promote its future retrieval. PIM is organic as we adapt it by repeatedly revisiting and restructuring our actions to the actual need and tasks, including the occasional deletion of old or irrelevant pieces of information [85].

Among PIM tools, different reference management software, such as EndNote, RefWorks, or Zotero also have to be mentioned, while a different perspective opens by mind mapping to stimulate the creative and innovative use of information collected [86].

We can speak about personal knowledge management (PKM), as well. It is a way of coping with complex environmental changes and developments and is also deemed to be a form of sophisticated career and life management. It is an emerging concept that focuses not only on the importance of individual growth and learning, but on the technology and management processes, which have been traditionally associated with organizational knowledge management [87]. PKM is an extension of Knowledge Management (KM), about the possibility of which there are well-founded doubts [88]. Nonetheless, we can also accept the existence of PKM, if we accept the definition of knowledge management as "the process of creating and managing the conditions for the transfer and the use of knowledge" [89, p. 36].

PKM is not directly connected to information overload, at least not to the same extent as PIM does. The individual plays also a different role in it, first on account of PKM's close connection to the corporate world. Notwithstanding, in contrast to the traditional view of KM that is primarily concerned with managing organizational knowledge (including the knowledge that individuals possess), PKM is 'personal inquiry', i.e. it is the quest to find, connect, learn and explore [90]. Therefore, PKM's focus is on helping individuals to be more effective in personal, organizational and social environments [91].

The closeness of PIM and PKM appears in a new hybrid concept that integrates PIM, PKM and IL and is called personal knowledge and information management (PKIM). PKIM aims at improving the functioning of individuals in competitive environments. On the one hand, it is based on PKM. On the other hand, it focuses on individual assets of knowledge and information, mobilizing competences in building information and knowledge collections, along with their use. In other words, it is about learning and creating new information and knowledge [92].

No wonder that in connection with PIM, the expression 'personal archiving literacies' also may make sense. Information professionals might impart this type of literacy because PIM is coupled to several challenges, including the difficulty of managing large groups of files and creating metadata. Desktop search may help finding information, but it is often difficult to find what someone is looking 
for, when the object is not known or is not remembered [93]. Personal archiving literacies includes appreciating the future value of someone's files and remembering where personal information is stored, identifying information that needs to be preserved, deleting unneeded items and maintaining important files [94].

\section{Discussion}

This chapter investigated information overloads in its complexity by not only enumerating its sources, but emphasizing how it can be mitigated. The thrust of the argument was on utilising information architecture, applying information literacy, data literacy and other literacies, as well as making use of personal information management. Since the time, when it was recognised that excessive information impairs performance, and this phenomenon has been labelled 'information overload', its definitions have not changed substantially. On the other hand, the causes of IO have expanded parallel to the development of technology [8].

The amount of information, information-processing capacity, and available time are the intrinsic factors, while the characteristics of information, quality of information and personal factors can be regarded to be external [95]. These factors mutually influence each other and it is difficult to disentangle which is dominant under a given circumstance. What is certain is that the influence of some extraneous factors can be mitigated. Therefore, this chapter addressed the majority of these, focusing mainly on the personal side of the extraneous factors in the light of the potential tools, also making use of a set of critical agendas as follows:

1. Social approaches that are meant to encourage better information consumption practices;

2. Technological approaches to foster designing for better information consumption practices;

3. Social approaches to helping people become good contributors to information sources [96].

Agenda 1 and agenda 3 are relatively clearly tied to literacies, outlined in this chapter. Agenda 1 reflects more traditional literacies, while Agenda 3 takes producing information into consideration. Agenda 2 is close to approaches that were mentioned in regard to information architecture.

The apparent loss of gatekeepers, like reviewers, editors, librarians and others lead to the consequence that readers themselves had to become the gatekeepers [97]. Notwithstanding, this chapter has been conceived in the belief that gatekeeping is not lost definitely, thus not only information users, but information architects, and information professionals should be well-prepared themselves to alleviate the symptoms of IO [98].

As information overload has many faces, our argument tried to be as diverse as possible. Nonetheless, in this chapter those approaches dominated that connected more or less directly to the idea, expressed by Forte et al in their Interdisciplinary Literacy Framework [96]: Making people smarter instead of producing smarter computers.

\section{Summary}

Regardless of the various interpretations, information overload is perceived by many in different spheres. It hampers the flow of information and - to say the least - causes delays in decision making. Consequently, there is a need for mitigating information overload in academia, business environments and in everyday life information seeking.

Information technology both causes overload and offers tools for alleviating its symptoms. For the former role the capacity to store massive amounts of data can be blamed on account of the prevalence of social media and the abundance of data. The latter task falls within the competence of design and information architecture.

A broad and diverse sphere of activities in reducing information overload is related to the different ways of interacting with information by taking a critical stance that often materialises in making use of a number of different literacies. Adopting slow principles to information behaviour and applying personal information management tools can also play a role in avoiding being overloaded. 


\section{References}

1. Bawden, D., Robinson, L.: The Dark Side of Information: Overload, Anxiety and Other Paradoxes and Pathologies. Journal of Information Science 35(2), 180-191 (2009)

2. Rowley, J.: The wisdom hierarchy: representations of the DIKW hierarchy. Journal of Information Science 33(2), 163-180 (2007)

3. Schneider, R.: Research Data Literacy. In: Kurbanoglu S. et al (eds.) Worldwide Commonalities and Challenges In Information Literacy Research and Practice. pp. 134-140. Springer International, Cham (2013)

4. Tidline, T. J.: The mythology of information overload. Library Trends, 47(3), 485-506 (1999)

5. Davis, N.: IA strategy: Addressing the signatures of information overload. UXmatters February 2012. http://www.uxmatters.com/mt/archives/2012/02/ia-strategy-addressing-thesignatures-of-information-overload.php (2013)

6. Badke, W.: Information overload? Maybe not. Online 34(5), 52-54 (2010)

7. Davis, N.: Information Overload, Reloaded. Bulletin of the American Society for Information Science and Technology 37, 45-49 (2011)

8. Benselin, J. C., Ragsdell, G.: Information overload: The differences that age makes. Journal of Librarianship and Information Science 0961000614566341 (2015)

9. Himma, K.E.: The concept of information overload: A preliminary step in understanding the nature of a harmful information-related condition. Ethics and Information Technology 9(4), 259-272 (2007)

10. Eppler, M J., Mengis, J.: The concept of information overload: A review of literature from organization science, accounting, marketing, MIS, and related disciplines. The Information Society 20(5), 325-344 (2004)

11. Butcher, H.: Meeting managers' information needs. London: Aslib (1998)

12. Davis, N.: Understanding Information Architecture Differently. UXmatters, May 2012, http://www.uxmatters.com/mt/archives/2012/05/understanding-information-architecturedifferently.php (2012)

13. Hargittai, E., Neuman, W.R., Curry, O.: Taming the information tide: Perceptions of information overload in the American home. The Information Society 28(3), 161-173 (2012)

14. Hemp, P.: Death by information overload. Harvard Business Review 87(9), 83-89 (2009)

15. Buckland, M.: Information as thing. Journal of the American Society for Information Science and Technology 42(5), 351-360 (2011)

16. Kari, J.: Conceptualizing the personal outcomes of information. Information Research 12(2), paper 292, Retrieved from http://InformationR.net/ir/12-2/paper292.html (2007)

17. Ulijn, J., Strother, J.: The influence of culture on in information overload. In: Strother, JB, Ulijn, J., Fazal, Z. (eds.) Information Overload: An International Challenge for Professional Engineers and Technical Communicators. pp. 79-98. John Wiley \& Sons, New York, NY (2007)

18. Savolainen, R.: Filtering and withdrawing: strategies for coping with information overload in everyday contexts. Journal of Information Science 33(5), 611-621 (2007)

19. Savolainen, R.: Everyday life information seeking: approaching information seeking in the context of way of life, Library and Information Science Research 17, 259-294 (2007)

20. Mawby, J., Foster, A., Ellis, D.: Everyday life information seeking behaviour in relation to the environment: Disposable information? Library Review 64(6-7), 468-479 (2015)

21. Poirier, L., Robinson, L.: Informational balance: slow principles in the theory and practice of information behaviour. Journal of Documentation 70(4), 687-707 (2014)

22. Bradford, P., Wurman R.S.: Information architects. Graphis, Zürich (1996)

23. Borgman, Ch.: The conundrum of sharing research data. Journal of the American Society for Information Science and Technology 63(6), 1059-1078 (2012)

24. Boyd, D., Crawford, K.: Critical questions for big data: Provocations for a cultural, technological, and scholarly phenomenon. Information, Communication and Society 15(5), 662-679 (2012)

25. Zikopoulos, P. et al.: Big Data Beyond the Hype. A Guide to Conversations for Today's Data Center. McGraw Hill Education, New York, NY, etc. (2015) 
26. Schreibman, S., Siemens, R., Unsworth, J.: The Digital humanities and humanities computing: An introduction. In: Schreibman, S., Siemens, R., Unsworth, J. (eds.) A Companion to Digital Humanities pp. XXIII-XXVII. Blackwell, Oxford (2004)

27. Gibbs, F.: Critical discourse in digital humanities. Journal of Digital Humanities Vol. 1 No. 1, http://journalofdigitalhumanities.org/1-1/critical-discourse-in-digital-humanities-by-fredgibbs/ (2011)

28. Alvarado, R.: The Digital Humanities Situation. In: Gold, M.K (ed.) Debates in the Digital Humanities. University of Minnesota Press. Minneapolis, MI http://dhdebates.gc.cuny.edu/debates/text/50A (2012)

29. Schöch, Ch.: Big? Smart? Clean? Messy? Data in the Humanities. Journal of Digital Humanities Vol. 2 No. 3, 2-13, http://journalofdigitalhumanities.org/2-3/big-smart-cleanmessy-data-in-the-humanities/ (2013)

30. Schmidt, B.M.: Theory first. Journal of Digital Humanities 1(1) http://journalofdigitalhumanities.org/1-1/theory-first-by-ben-schmidt/ (2011)

31. Piez, W.: Something Called Digital Humanities. DHQ: Digital Humanities Quarterly 2(1) http://www.digitalhumanities.org/dhq/vol/2/1/000020/000020.html (2008)

32. Dalbello, M.: A genealogy of digital humanities. Journal of Documentation 67(3), 480-506 (2011)

33. Frabetti, F.: Rethinking the digital humanities in the context of originary technicity. Culture Machine Vol. 12, 1-22 (2011)

34. Dillon, A.: Library and information science as a research domain: problems and prospects." Information Research 12(4), http://InformationR.net/ir/12-4/colis/colis03.html (2007)

35. Neylon, C.: It's not filter failure, it's a discovery deficit. Serials 24(1), 21-25 (2011)

36. Katzer, J., Fletcher, P.T.: The information environment of managers. Annual Review of Information Science and Technology 27, 227-263 (1992)

37. Edmunds, A., Morris, A.: The problem of information overload in business organisations: a review of the literature. International Journal of Information Management 20(1), 17-28 (2000)

38. Blummer, B., Kenton, J.M.: Reducing patron information overload in academic libraries. College, \& Undergraduate Libraries, 21(2), 115-135 (2014)

39. Davis, N.: The function of information architecture. DSIA Portal of Information Architecture. http://www.methodbrain.com/dsia/the-basics-of-ia/The-Basic-Function-of-IA.cfm (2010)

40. Brown, D.: Eight Principles of Information Architecture. Bulletin of the American Society for Information Science and Technology 36(6), 30-34 (2005)

41. Morville, P.: Ambient Findability. O'Reilly, Sebastopol, CA (2005)

42. Huang, Y.M. et al.: Designing a Personalized Guide Recommendation System to Mitigate Information Overload in Museum Learning. Educational Technology \& Society 15 (4), 150$166(2012)$

43. Hinton, A.: The Machineries of Context: New Architectures For a New Dimension. Journal of Information Architecture 1, 37-47 (2009)

44. Huvila, I.: The Complete Information Literacy? Unforgetting Creation and Organization of Information. Journal of Librarianship and Information Science 43, 237-245 (2011)

45. Keen, A.: The Cult of the Amateur. Nicholas Brealey Publishing, London (2007)

46. Leadbeater, C., Miller, P.: Pro-Am revolution: how enthusiasts are changing our economy and society. Demos, London (2004)

47. Reid, P. H., Macafee, C.: The philosophy of local studies in the interactive age. Journal of Librarianship and Information Science 39(3), 126-141 (2007)

48. Framework for Information Literacy for Higher Education. Association of College and Research Libraries, Chicago, IL (2015)

49. Jones, D.: Critical Thinking in an Online World. University of California, Santa Barbara Library, Santa Barbara, CA http://misc.library.ucsb.edu/untangle/jones.html (1996)

50. The SCONUL Seven Pillars of Information Literacy Core Model for Higher Education. London: SCONUL Working Group on Information Literacy, London http://www.sconul.ac.uk/sites/default/files/documents/researchlens.pdf (2011)

51. Information Literacy Competency Standards for Higher Education. Association of College and Research Libraries, Chicago, IL (2000) 
52. Livingstone, S.: Media Literacy and the Challenge of New Information and Communication Technologies. Communication Review 7, 3-14 (2004)

53. Livingstone, S., van Couvering, E.J., Thumim, N.: Converging Traditions of Research on Media and Information Literacies: Disciplinary and Methodological Issues. In: Leu, D.J., et al (eds.) Handbook of Research on New Literacies, pp. 103-132. Lawrence Erlbaum Associates, Hillsdale, MI (2008)

54. Buschman, J.: Information literacy, new literacies and literacy, Library Quarterly 79(1), 95118 (2009)

55. Street, B.: (2008). New literacies, new times: Developments in literacy studies. In: Encyclopedia of language and education (pp. 418-431). Springer, New York, NY. (2008)

56. Lankshear, C., Knobel, M.: "New" Literacies: Research and Social Practice. http://everydayliteracies.net/pubs.html (2004)

57. Bawden, D.: Information and Digital Literacies: A Review of Concepts. Journal of Documentation 57, 218-259 (2001)

58. Ji, Q., Ha, L., Sypher, U.: The role of news media use and demographic characteristics in the possibility of information overload prediction. International Journal of Communication 8(16), 699-714 (2014)

59. Campbell, B.: What is literacy? Acquiring and using literacy skills. Australasian Public Libraries and Information Services, 3, 149-152 (1990)

60. Cordes, S.: Broad horizons: The role of multimodal literacy in 21 st century library instruction. http://www.ifla.org/files/hq/papers/ifla75/94-cordes-en.pdf (2009)

61. D’Angelo, B.J., Maid, B.M.: Moving beyond definitions: Implementing information literacy across the curriculum. Journal of Academic Librarianship 30(3), 212-217 (2004)

62. Greater expectations: A new vision for learning as a nation goes to college. Association of American Colleges and Universities, Washington, DC www.greaterexpectations.org/pdf/GEX.FINAL.pdf (2004)

63. Nazari, M., Webber, S.: Loss of faith in the origins of information literacy in e-environments: Proposal of a holistic approach. Journal of Librarianship and Information Science 44(2), 97 107 (2012)

64. Boekhorst, A.: Becoming information literate in the Netherlands. Library Review 52 (7), 298309 (2012)

65. ALA Presidential Committee on Information Literacy. Final report. American Library Association, Chicago, IL (1989)

66. Špiranec, S., Banek Zorica, M.: Information Literacy 2.0: hype or discourse refinement? Journal of Documentation 66(1), 140-153 (2010)

67. Mackey, T.P., Jacobson, T.E.: Reframing Information Literacy as a Metaliteracy. College and Research Libraries 72(1), 62-78 (2011)

68. Ipri, T.: Introducing transliteracy. What does it mean to academic libraries? College \& Research Libraries News 71(10), 532-567 (2010)

69. Murray, M.C., Pérez, J.: Unraveling the Digital Literacy Paradox: How Higher Education Fails at the Fourth Literacy. Issues in Informing Science and Information Technology 11, 85100, http://iisit.org/Vol11/IISITv11p085-100Murray0507.pdf (2010)

70. Martin, A.: Literacies for the digital age. In: Martin, A., Madigan, D. (eds.) Digital Literacies for Learning, pp. 3-25. Facet, London (2006)

71. Meyers, E.M., Erickson, I., Small, R.V.: Digital literacy and informal learning environments: an introduction. Learning, Media and Technology 38(4), 355-367 (2013)

72. Bawden, D.: Origins and Concepts of Digital Literacy. In: Lankshear, C., Knobel, M (eds.) Digital Literacies: Concepts, Policies and Practices, pp. 17-32. Peter Lang, New York (2008)

73. Koltay, T.: Data literacy: in search of a name and identity. Journal of Documentation 71(2), 401-415 (2015)

74. Johnson, C.A.: The information diet: A case for conscious consumption. O'Reilly, Sebastopol, CA (2012)

75. Ridsdale, C. et al.: Strategies and Best Practices for Data Literacy Education. Knowledge Synthesis Report. Dalhousie University, Halifax, NS (2015) 
76. Giarlo, M.: Academic Libraries as Quality Hubs. Journal of Librarianship and Scholarly Communication 1(3), 1-10 (2013)

77. Intersections of scholarly communication and information literacy: Creating strategic collaborations for a changing academic environment. Association of College and Research Libraries, Chicago, IL http://acrl.ala.org/intersections/ (2013)

78. Carlson, J. et al.: Determining data information literacy needs: A study of students and research faculty. portal: Libraries and the Academy 11(2), 629-657 (2011)

79. Calzada Prado, J.C., Marzal M.Á. (2013) Incorporating data literacy into information literacy programs: Core competencies and contents. Libri 63(2), 123-134.

80. Davies, A., Fidler, D., Gorbis, M.: Future work skills 2020. Institute for the Future, Palo Alto, CA http://www.iftf.org/our-work/global-landscape/work/future-work-skills-2020/ (2011)

81. Bergman, O.: Variables for personal information management research. Aslib Proceedings 65(5), 464-483 (2013)

82. Jones, W.: Keeping found things found: The study and practice of personal information management. Morgan Kaufmann Publishers, Boston, MA (2008)

83. Franganillo, J.: Gestión de información personal: elementos, actividades e integración. El Profesional de la Información 18(4), http://franganillo.es/gip.pdf (2009)

84. Cushing, A.L.: "If it computes, patrons have brought it in": Personal information management and personal technology assistance in public libraries. Library and Information Science Research 38(1), 81-88 (2016)

85. Whittaker, S.: Personal Information Management: From Information Consumption to Curation. In: Cronin, B. (ed.) Annual Review of Information Science and Technology 45, 1-62. Information Today Inc., Medford, NJ (2011)

86. Fourie, I.: Personal information management (PIM), reference management and mind maps: the way to creative librarians? Library Hi Tech 29(4), 764-771 (2011)

87. Pauleen, D., Gorman, G.: Personal Knowledge Management: Individual, Organizational and Social Perspectives. Gower, Farnham (2011)

88. Wilson, T. D.: The nonsense of knowledge management. Information Research 8(1), 8-1 (2002)

89. Brophy, P.: The Library in the Twenty-first Century: New services for the information age. London: Library Association Publishing (2001)

90. Clemente, B.E., Pollara, V.J.: Mapping the course, marking the trail. IT Professional 7(5), 1015 (2005)

91. Pauleen, D.: Personal knowledge management: Putting the person back into the knowledge equation. Online Information Review 33(2), 221-224 (2009)

92. Świgoń, M.: Personal knowledge and information management-conception and exemplification. Journal of Information Science 39(6), 832-845 (2013)

93. Marshall, C.C., Bly, S., Brun-Cottan, F.: The long term fate of our digital belongings: Toward a service model for personal archives. Archiving Conference 2016, pp. 25-30, Society for Imaging Science and Technology, Springfield, VA (2006)

94. Zastrow, J.: PIM 101: Personal information management. Computers in Libraries 34(2), 22-24 (2014)

95. Jackson, T.W., Farzaneh, P.: Theory-based model of factors affecting information overload. International Journal of Information Management 32(6), 523-532 (2012)

96. Forte, A. et al.: Designing Information Savvy Societies: An Introduction to Assessability. In: Proceedings of ACM SIGCHI Conference on Human Factors in Computing Systems (CHI14), Toronto, Canada. http://www.andreaforte.net/ForteCHI14Assessability.pdf (2014)

97. Badke, W.: Research Strategies: Finding your Way through the Information Fog. 2nd ed., Lincoln, NE: iUniverse.com (2004)

98. Koltay, T.: Information overload, information architecture and digital literacy. Bulletin of the American Society for Information Science and Technology 38(1), 33-35. http://www.asis.org/Bulletin/Oct-11/OctNov11_Koltay.pdf (2011) 